Tropical Journal of Pharmaceutical Research February 2011; 10 (1): 11-17

(C) Pharmacotherapy Group, Faculty of Pharmacy, University of Benin,

Benin City, 300001 Nigeria.

All rights reserved.

Research Article

Available online at http://www.tjpr.org

\title{
Perceptions of Hospital Pharmacist's Role in Pakistan's Healthcare System: A Cross-Sectional Survey
}

\section{Saira Azhar, Mohamed A Hassali* and Mohamed MI Ibrahim}

Discipline of Social and Administrative Pharmacy, School of Pharmaceutical Sciences, Universiti Sains Malaysia, 11800 Minden, Penang, Malaysia

\begin{abstract}
Purpose: To investigate hospital pharmacists' perception of their current clinical role in Pakistan's healthcare system.

Methods: This was a cross-sectional study in a population that consisted of hospital pharmacists in Islamabad, Faisalabad and Lahore which are three cities in Punjab State, Pakistan. A sample of 116 hospital pharmacists was selected from public and private hospitals in these three cities.

Results: At least $42.2 \%$ of the hospital pharmacists were involved in patient education pertaining to drugs. Although they were willing to take personal responsibility for resolving drug-related problems encountered, $84.5 \%$ of them conveyed that their current role is more focused on pharmacy record keeping. Only $57.8 \%$ of the pharmacist indicated that they were involved in compiling and updating of their hospital's drug formulary.

Conclusion: The findings suggest that hospital pharmacists in Pakistan do have concerns about their present professional roles and face significant barriers with regards to increasing their involvement in clinical services. However, they need to be proactive in their collaboration with other healthcare professionals if the concept of pharmaceutical care is to take root in the healthcare system.
\end{abstract}

Keywords: Hospital pharmacist, Pharmacy practice, Healthcare system, Perception, Pakistan. 


\section{INTRODUCTION}

The roles of pharmacists are developing rapidly to keep pace with the needs of an advanced healthcare system. Pharmacists recognize the need to play important roles in the safe and rational use of medicines and are willing to accept this responsibility to ensure maximum therapeutic benefit [1]. Furthermore, they are continuously being challenged to become key players in the prescribing process, as well as optimising and monitoring drug use [2].

In the developed world, professional relationship between the prescriber and pharmacists is good [3] but in developing countries, the pharmacy profession still faces a lot of barriers, among which are acute shortage of qualified pharmacists and lack of standard practice guidelines [4]. Moreover, pharmacists in the developing world prefer to work in cities and are thus concentrated in urban areas - a situation that militates against the provision of uniform nationwide pharmacy services [5]. Lack of appropriate and quality medicines as well as unconventional use of medicine and weak regulatory enforcement of drug sales are also serious issues in developing countries [6].

It has been estimated that around 8102 pharmacists are in Pakistan with 2,836 working in the public sector, 5,023 in private settings and 243 in non-governmental nonprofit organizations [7]. Of the total, approximately $55 \%$ are involved in the production of pharmaceuticals, $15 \%$ in federal and provincial drug control and hospital pharmacy establishments, another $15 \%$ in the sales and marketing of pharmaceuticals, $10 \%$ in community pharmacy, and $5 \%$ in teaching and research

Pakistan health authorities have sought to implement pharmaceutical care services within the nation's healthcare system in order to improve patients' quality of life and medicines use [9]. Successful implementation of pharmaceutical care requires cooperation between hospital pharmacists and other healthcare professionals. The number of pharmacists in both public and private sectors is small but has been increasing over the past few years. However, hospital pharmacists tend to focus more on managerial matters than on clinical services [9]. Therefore, the aim of this study was to explore the perception of Pakistani hospital pharmacists regarding their role in hospital settings.

\section{METHODS}

\section{Design}

This study was a cross-sectional survey. The questionnaire had six sections: (i) demographic information, (ii) pharmacist's interaction with doctors on patient's medication, (iii) current clinical role in the hospital, (iv) experience with other healthcare professionals, (v) perception of current pharmacy curriculum, and (vi) views on Pakistan Pharmacists' Association.

Each section of the questionnaire included a set of statements against which the respondents were asked to indicate the level of agreement using a 4-point Likert scale, with 1 = strongly disagree, 2 = disagree, $3=$ agree, 4 = strongly agree. This scale was used in order to avoid confusion with 'neutral' responses. In addition, some questions required a "yes" or "no" response.

\section{Reliability and validity analysis}

To assess content validity, the preliminary version of the questionnaire consisting of 43 items was sent to four professionals at the School of Pharmacy, Universiti Sains Malaysia USM. These professionals were asked to assess the questionnaire by providing their overall opinion and by listing the questions in the order of relevance and importance. The questions that were of more relevance and importance were highlighted.

To assess face validity of the questionnaire, two focus groups consisting of thirty 
participants (15 per group) were solicited. These participants were asked for their views on the significance, worth, and simplicity of each question and to identify which questions they would wish to be removed in order to make the questionnaire brief. In addition to this, the participants were also requested to indicate whether the questions were understandable or not. The reliability test was applied to all the variables comprising the knowledge domain. The reliability of the tool was estimated on the basis of Cronbach's Alpha (ó = 0.76).

\section{Sample and sampling procedure}

The study was conducted from January through March 2009 in Punjab State, Pakistan. The study population consisted of full-time hospital pharmacists in the three cities of Punjab state - Islamabad, Faisalabad and Lahore - which form an arc that makes up the majority of southern Pakistan's population living along the Indus River [10].

Non-probability convenient sampling was adopted for data collection. The reason for adopting this method of sampling was the absence of a database indicating the exact number of hospital pharmacists working in the hospitals concerned. Therefore, a survey was carried out, prior to the data collection, to identify those hospitals where there is always a hospital pharmacist on duty during work hours. A total of 35 hospitals were assessed, with a total of 150 hospital pharmacists performing their duties. The health facilities visited had 20 pharmacists enrolled in Lahore, 10 in Islamabad and 5 in Faisalabad. Out of the 150 questionnaires distributed, 116 were returned, giving a response rate of 77.3 $\%$ as follows: Islamabad $(n=22)$, Faisalabad $(n=4)$ and Lahore $(n=90)$.

The participants were contacted and given an explanation of the purpose of the study and they gave verbal consent to participate in the study. The questionnaires were handdelivered by a data collection team.

\section{Data analysis}

Non-parametric statistical test and appropriate descriptive and inferential statistics were applied to the demographic characteristics, and perception scales were performed using SPSS ${ }^{\circledR}$ for Windows, version 15 (SPSS Inc). The demographic information collected include age, gender, type of hospital, years of practice, and frequencies. Fisher's Exact test was used to test the significance of association between the independent variables (age, gender, type of hospital, and years of practice) and the dependent variables (respondent's current role in the hospital, experience with other healthcare professionals, and perception regarding current pharmacy curriculum). Statistical significance was accepted at $p$ value of $\leq 0.05$.

\section{RESULTS}

Total of 166 questionnaires were returned from the three cities: Islamabad (22), Faisalabad (4) and Lahore (140). The demographic data of the respondents are summarized in Table 1. The mean age was $29.21 \pm 5.15$ years; $37.9 \%(n=44)$ were male and $62.1 \%(n=72)$ female.

Table 1: Hospital pharmacists' demographic information

\begin{tabular}{ll}
\hline Variable & $\mathbf{n}(\%)$ \\
\hline Age (mean: 29.21 55.15) & \\
$20-30$ & $82(70.7)$ \\
$31-40$ & $31(26.7)$ \\
$41-50$ & $2(1.7)$ \\
$>50$ & $1(0.9)$ \\
Gender & \\
Male & $44(37.9)$ \\
Female & $72(62.1)$ \\
Type of hospital & \\
Public hospital & $103(88.8)$ \\
Private hospital & $13(11.2)$ \\
Years of practice & \\
$<1$ & $14(12.1)$ \\
1-10 & $98(84.5)$ \\
$11-20$ & $4(3.4)$ \\
\hline
\end{tabular}


The participants' responses to questions on their interaction with doctors are summarized in Table 2. A majority of the pharmacists, $75.0 \%(n=87)$, said they were sometimes called by doctors who need advice in deciding a medicine for their patients while $62.9 \%(n=73)$ of the pharmacists contacted doctors for clarification if there was an important omission in a prescription. The main reason for doctors calling the pharmacists was to enquire about the availability of a medicine in the pharmacy $(86.2 \%, n=100)$, medicine alternatives (65.5 $\%, \mathrm{n}=76)$, medicine dosage information (60.3 $\%, n=70)$, side effects $(23.3 \%, n=27)$, and drug interaction $(32.8 \%, n=38)$.

Table 2: Level of interaction between pharmacists and doctors

\begin{tabular}{ll}
\hline Variable & $\mathbf{n}(\%)$ \\
\hline Doctors seek advice & \\
Never & $7(6.0 \%)$ \\
Some times & $87(75.0 \%)$ \\
Always & $22(19.0 \%)$ \\
Pharmacist contact doctors & \\
Never & $4(3.4 \%)$ \\
Some times & $73(62.9 \%)$ \\
Always & $39(33.6 \%)$ \\
Reasons for interactions & \\
Drug availability queries & $100(86.2)$ \\
Drug alternatives queries & $76(65.5)$ \\
Drug dosage queries & $70(60.3)$ \\
Side effect queries & $27(23.3)$ \\
Drug interaction queries & $38(32.8)$ \\
\hline
\end{tabular}

The current clinical roles of pharmacists in the hospitals are listed in Table 3 . Out of 116 pharmacists, $65.5 \%(\mathrm{n}=76)$ offered advice to patients on the use of alternative prescription medication. Around two-thirds of the respondents $69.8 \%(n=81)$ identified and prevented prescription errors and this was statistically significant with respect to gender $(p=0.015)$, with females in the majority. A large majority of the respondents, $77.6 \%(\mathrm{n}=90)$, were involved in patient counseling, and again this was significant with respect to gender $(p=0.049)$, with females in the majority, while $57.8 \%(n=67)$ of the pharmacists were involved in the compilation and updating of their hospital's drug formulary, and this was statistically significant with respect to age $(p=0.020)$. With respect to monitoring outcomes of pharmacotherapeutic regimens and plans, $66.4 \%(n=77)$ of the pharmacists were not involved; this was statistically significant with respect to gender $(p=0.040)$ and type of hospital $(p=0.029)$, while $56.0 \%$ of the pharmacists engaged in filling the medication order only. A majority of the hospital pharmacists were involved in record-keeping in the pharmacy and $97.4 \%$ were willing to take personal responsibility for resolving drug-related problems.

Table 4 indicates pharmacists' experience with other healthcare professionals in the hospital setting. A large proportion of the respondents $(74.1 \%)$ strongly agree that better patient care would be achieved by team work involving all healthcare professionals. Half of the pharmacists (50.9 $\%$ ) agreed while $41.4 \%$ strongly agreed that pharmacists are a reliable source of clinical drug information for patients and other healthcare professionals. When the respondents were asked about collaborative relationship among pharmacists, doctors and nurses, only half $(51.7 \%)$ of the respondents agreed that there was. A little over half of the pharmacists $(56.0 \%)$ agreed that pharmacists' suggestions on patient medication were taken into consideration by physicians.

Hospital pharmacists' perceptions of the pharmacy curriculum are summarized in Table 5 , and it shows that $53.4 \%(n=62)$ of the hospital pharmacists disagreed when they were asked if the pharmacy curriculum measured up to the defined standard. There was statistically significant difference $(p=$ 0.030 ) in their response with respect to type of hospitals (public and private). With regard to whether the pharmacy curriculum covers all aspects of pharmacy practice, $48.3 \%$ ( $n=$ 56) of the pharmacists disagreed, and the response varied significantly $(p=0.003)$ with age. When they were asked if they were satisfied with the undergraduate pharmacy 
curriculum, $56.0 \%$ of the respondents disagreed. When it came to the issue of the relative distribution of theoretical and practical aspects of the curriculum, $67.2 \%$ (n $=78$ ) of the pharmacists disagreed there was a good balance between the two aspects, and the difference was statistically significant
( $p=0.001$ ) with respect to age. Slightly over half of the pharmacists, i.e., $56.9 \%(n=66)$ agreed that the recent introduction of the 5year Doctor of Pharmacy (Pharm D) undergraduate degree programme in all Pakistani pharmacy schools will help groom better pharmacy practitioners.

Table 3: Clinical roles of pharmacists (all respondents) in the hospitals

\begin{tabular}{|c|c|c|c|c|c|c|}
\hline \multirow{2}{*}{$\begin{array}{c}\text { Item no. in } \\
\text { questionnaire }\end{array}$} & \multicolumn{2}{|c|}{ Responses } & \multicolumn{4}{|c|}{ p-value (Fisher's Exact test ) } \\
\hline & Yes & No & Age & Gender & $\begin{array}{l}\text { Type of } \\
\text { hospital }\end{array}$ & $\begin{array}{l}\text { Year of } \\
\text { practice }\end{array}$ \\
\hline 1 & $49(42.2 \%)$ & $67(57.8 \%)$ & 0.577 & 0.450 & 0.375 & 0.495 \\
\hline 2 & $46(39.7 \%)$ & $70(60.3 \%)$ & 0.843 & 0.114 & 0.208 & 0.529 \\
\hline 3 & $75(64.7 \%)$ & $41(35.3 \%)$ & 0.138 & 0.351 & 0.513 & 0.188 \\
\hline 4 & $57(41.1 \%)$ & $59(50.9 \%)$ & 0.329 & 0.334 & 0.302 & 0.086 \\
\hline 5 & $81(69.8 \%)$ & $35(30.2 \%)$ & 0.510 & 0.015 & 0.345 & 0.365 \\
\hline 6 & $33(28.4 \%)$ & $83(71.6 \%)$ & 0.303 & 0.500 & 0.068 & 0.988 \\
\hline 7 & $90(77.6 \%)$ & $26(22.4 \%)$ & 0.619 & 0.049 & 0.595 & 0.168 \\
\hline 8 & $39(33.6 \%)$ & $77(66.4 \%)$ & 0.245 & 0.040 & 0.029 & 0.251 \\
\hline 9 & $55(47.4 \%)$ & $61(52.6 \%)$ & 0.267 & 0.082 & 0.580 & 0.098 \\
\hline 10 & $67(57.8 \%)$ & $49(42.2 \%)$ & 0.020 & 0.056 & 0.507 & 0.122 \\
\hline 11 & $65(56.0 \%)$ & $51(44.0 \%)$ & 0.823 & 0.525 & 0.238 & 0.445 \\
\hline 12 & $98(84.5 \%)$ & $18(15.5)$ & 0.606 & 0.244 & 0.098 & 0.263 \\
\hline 13 & $113(97.4 \%)$ & $3(2.6 \%)$ & 0.735 & 0.679 & 0.698 & 0.754 \\
\hline
\end{tabular}

${ }^{*}$ Reported responses were for all respondents; 1 = Provide patient education pertaining to drugs; $2=$ Suggest use of nonprescription medicine; $3=$ Suggest use of certain prescription medications to patients; $4=$ Suggest use of certain prescription medications to physicians; $5=$ Identify and prevent prescription errors; $6=$ Design and monitor pharmacotherapeutic regimens; $7=$ Involvement in patient counseling; 8= Monitor outcomes of pharmacotherapeutic regimens and plans; $9=$ Involvement in the development of policies and guidelines for hospital regulations; $10=$ Involvement in compilation and updating of their hospital's drug formulary; $11=$ Fill medication order only; 12= Maintain the recordkeeping in the pharmacy; 13= Willing to take personal responsibility for resolving drug-related problems.

Table 4: Pharmacists' (all respondents) experience with other healthcare professionals

\begin{tabular}{ccccccccc}
\hline $\begin{array}{c}\text { Item no. } \\
\text { in Ques- } \\
\text { tionnaire }\end{array}$ & SD & \multicolumn{2}{c}{$\begin{array}{c}\text { Responses, } \mathbf{n}(\%) \\
\text { D }\end{array}$} & A & SA & Age $\begin{array}{c}\boldsymbol{p} \text {-value (Fisher's Exact test) } \\
\text { Gende } \\
\text { r }\end{array}$ & $\begin{array}{c}\text { Type of } \\
\text { hospital }\end{array}$ & $\begin{array}{l}\text { Year of } \\
\text { practice }\end{array}$ \\
\hline 1 & & & & & & 0.773 & 0.558 & 0.699 \\
2 & $3(2.6 \%)$ & $3(2.6 \%)$ & $24(20.7 \%)$ & $86(74.1 \%)$ & 0.862 & 0.757 & 0.761 \\
3 & $3(2.6 \%)$ & $5(4.3 \%)$ & $51(44.0 \%)$ & $57(49.1 \%)$ & 0.816 & 0.928 & 0.247 & 0.761 \\
4 & $4(3.6 \%)$ & $6(5.2 \%)$ & $59(50.9 \%)$ & $48(41.4 \%)$ & 0.821 & 0.940 & 0.398 & 0.862 \\
5 & $4(3.4 \%)$ & $33(28.4 \%)$ & $60(51.7 \%)$ & $19(16.4 \%)$ & 0.339 & 0.522 & 0.817 & 0.479 \\
\hline
\end{tabular}

$S D=$ Strongly disagree; $D=$ Disagree; $A=$ Agree; $S A=$ Strongly agree; 1 = Patient care can be achieved by team work of all healthcare professionals; 2 = Pharmacists are seen as a reliable source of drug information for patient and other healthcare professionals; 3 = Pharmacists are a reliable source of clinical drug information for patients and other healthcare professionals; 4 = Collaborative relationship exists between pharmacists, doctors and nurses in the hospital; $5=$ Pharmacist's suggestion is taken into consideration by physicians. 
Azhar et al

Table 5: Perception regarding current pharmacy curriculum

\begin{tabular}{ccccccccc}
\hline $\begin{array}{c}\text { Item no. } \\
\text { in ques- } \\
\text { tionnaire }\end{array}$ & SD & R & A & SA & Age & $\begin{array}{c}\text { G-value (Fisher's Exact test) } \\
\text { r }\end{array}$ & $\begin{array}{c}\text { Type of } \\
\text { hospital }\end{array}$ & $\begin{array}{c}\text { Year of } \\
\text { practice }\end{array}$ \\
\hline 1 & $6(5.2 \%)$ & $62(53.4 \%)$ & $42(36.2 \%)$ & $6(5.2 \%)$ & 0.633 & 0.346 & 0.030 & 0.899 \\
2 & $5(4.3 \%)$ & $56(48.3 \%)$ & $48(41.4 \%)$ & $7(6.0 \%)$ & 0.003 & 0.862 & 0.165 & 0.330 \\
3 & $4(3.4 \%)$ & $60(51.7 \%)$ & $44(37.9 \%)$ & $8(6.9 \%)$ & 0.086 & 0.203 & 0.088 & 0.806 \\
4 & $8(6.9 \%)$ & $65(56.0 \%)$ & $40(34.5 \%)$ & $3(2.6 \%)$ & 0.073 & 0.083 & 0.056 & 0.098 \\
5 & $7(6.0 \%)$ & $78(67.2 \%)$ & $25(21.6 \%)$ & $6(5.2 \%)$ & 0.001 & 0.422 & 0.634 & 0.003 \\
6 & $5(4.3 \%)$ & $25(21.6 \%)$ & $66(56.9 \%)$ & $20(17.2 \%)$ & 0.565 & 0.638 & 0.357 & 0.763 \\
\hline
\end{tabular}

$\mathrm{SD}=$ Strongly disagree; $\mathrm{D}=$ Disagree; $\mathrm{A}=$ Agree; $\mathrm{SA}=$ Strongly agree; 1 = Pharmacy curriculum measures up to the defined standard; 2 = Curriculum covers all the aspects of pharmacy practice; $3=$ Curriculum also covers clinical aspects of the pharmacy practice; $4=$ Satisfied with the pharmacy curriculum at undergraduate level; $5=$ Satisfied with the balance of theoretical and practical aspects of the curriculum; $6=$ Current introduction of 5-year Pharm D program in Pakistani pharmacy schools, will help to develop better practitioners

\section{DISCUSSION}

Pharmaceutical care, as an integral part of pharmacy practice in developing countries, varies significantly from one country to another. Until recently, the number of pharmacists employed in hospitals in the public sector was small. Even then, their role is largely limited to drug dispensing, procurement and inventory management [11]. To establish pharmaceutical care services effectively, understanding of the hospital pharmacist's perception of the concept, especially with regard to their role and interactive experience with other healthcare professionals, is vital. This initial step will facilitate the development of strategies to provide maximum care to the patient.

The findings of this study show that interaction between the pharmacist and doctors is low, and are consistent with an earlier qualitative study [12] which observed that although Pakistani doctors consider the pharmacist as an integral part of the healthcare team, the number of pharmacists was grossly inadequate. A majority of the respondents in our study indicated that they do not provide medication education to patients. A study by Bonnie [13] stressed the need for pharmacists to play more a active role in patient counseling as this can significantly reduce patient non-adherence to medication. Unfortunately, in Pakistan, the health care system is yet to fully recognize the pharmacist's role and this is reflected by their limited interaction with the patient and their tendency to focus more on managerial issues than on patient care.

A majority of the respondents did not agree that they should recommend non-prescription medicines to patients probably because at the moment, Pakistani pharmacists are not trained to perform this role and, in any case, do not have the confidence to do so. A major factor which may contribute to this is the inadequacy of the current undergraduate pharmacy curriculum [14], especially defficiency in clinical training, as has been identified in countries where pharmaceutical care is in its early stage of development $[15,16]$. Interestingly, a majority of the respondents, in each case, were not satisfied with the undergraduate pharmacy curriculum and the balance between the theoretical and practical components of the curriculum. It is hoped that with the recent commencement of the Pharm D program in Pakistani pharmacy schools, the issues raised with regard to curriculum, lack of experienced teachers and absence of practice-based facilities will also be addressed [14].

Only a small majority of pharmacists indicated that doctors usually considered 
their suggestions on patient medication, a finding that is supported by previous studies which showed that doctors are reluctant to accept any pharmacist's role that includes anything that has to do with prescribing $[17,18]$.

\section{CONCLUSION}

Hospital pharmacists in Pakistan clearly have concerns about their present professional roles as they face considerable barriers with regard to the provision of a range of quality clinically-focused pharmacy services. These challenges include shortage of pharmacists in hospitals and too much focus on traditional duties rather than patient-orientated pharmaceutical care. However, pharmacists need to be proactive by seeking greater interaction and collaboration with other healthcare professionals as this would help pave the way for the concept of pharmaceutical care to be instituted in the Pakistani health care system

\section{REFERENCES}

1. FIP statement of policy on good pharmacy education and practice [database on the Internet]. 2000 [cited 12 May 2008]. Available from: http://www.fip.org/www/uploads/data.

2. Hughes CM, McCann S. Perceived interprofessional barriers between community pharmacists and general practitioners: a qualitative assessment. Br J Gen Pract 2003; 53: 600-606.

3. Adepu R, Nagavi BJ. General practitioners perception about the extended role of the community pharmacist in the state of Kamataka: a study. Indian J Pharm Sci. 2006; 68: 36-40.

4. Sing WS. Pharmacy Practice in Malaysia. Malaysian J PharmI Sci 2001; 1(1): 3-9.
5. Smith F. Community Pharmacy in Ghana: Enhancing the contribution to primary health care. Health Policy Plan 2004; 19(4): 234-241.

6. Farris KB, Llimos FF, Benrimoj S. Pharmaceutical Care in Community Pharmacies: Practice and Research from Around the World. Ann Pharmacother 2005;39.

7. WHO, UNCF, DFID, TWB. Report of Health System Review Mission Pakistan. 2007 [updated 2007; cited 200725 Sep]; Available from. http://gis. emro.who.int/healthsystemobservatory/pdf

8. Ahsan N. Pharmacy Education and Pharmacy Council of Pakistan Drug Update. 2005.

9. Azhar S, Hassali MA, Ibrahim MI. Doctors' perception and expectations of the role of the pharmacist in Punjab Pakistan. Trop J Pharm Res 2010; 9(3): 205-212.

10. WHO. Working Together for Health: The World Health Report 2006.

11. Azhar S, Hassali MA, Mohamed Ibrahim MI, Ahmad M, Masood I, Shafie AA. The role of pharmacists in developing countries: the current scenario in Pakistan. Hum Resour Health 2009; 7(1):54.

12. Azhar S, Hassali MA. Evaluating the perception of doctors towards the role of pharmacist in Pakistan's healthcare system. Malaysian $J$ Pharm Sci 2009; 1(7): 105.

13. Bonnie L, Svarstad, Bultman DC, Mount JK. Patient counseling provided in community pharmacies: effects of state regulation, pharmacist age, and busyness. J Am Pharm Assoc 2004; 44(1): 17.

14. Jamshed $S$, Babar ZU, Ibrahim MIM. Pharm $D$ in Pakistan: a tag or a degree? Am J Pharm Educ 2009; 73(1): 13.

15. Awad A, Matowe L, Capps P. Medical doctors perceptions and expectations of the role of hospital pharmacist in Sudan. Pharm World Sci 2007; 29: 557-564.

16. Matowe L, Abahussain EA, Al-Saffar N, Bihzad SM, Al-Foraih A. Physicians' perception and expectations of pharmacists' professional duties in government hospital in Kuwait. Med Princ Pract 2006; 15(6): 185-189.

17. Ritchey FJ, Raney MR. Effect of exposure on physicians' attitudes toward clinical pharmacists. Am J Health Syst Pharm 1981; 38(10): 1459-1463.

18. Spencer JA, Edwards C. Pharmacy beyond the dispensary: general practitioners' views. BMJ 1992; 304(6843): 1670-1672. 